\section{Práctica del fútbol en España: inmigración e integración social}

\author{
Soccer practice in Spain: \\ immigration and social integration
}

\section{Palabras clave \\ - Integración social \\ - Inmigrantes \\ - Deporte \\ - Fútbol}

\section{Key words \\ - Social integration \\ - Immigrants \\ - sports \\ - Football}

Zakariae Cheddadi El Haddad Universidad del País Vasco- Euskal Herriko Unibertsitatea (UPV-EHU) zakariae.cheddadi@ehu.eus ORCID iD: https://orcid.org/0000-0001-7363-2760

\author{
ORCID iD: https://orcid.org/0000-0001-7363-2760
}

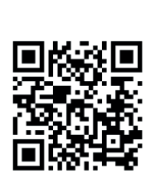

\title{
Resumen
}

Tras un breve descenso de los flujos migratorios desde la crisis del 2008, la inmigración ha recobrado protagonismo, retornando a los datos previos a la crisis económica. En este contexto aparece el debate sobre la integración social de las personas inmigradas extranjeras, en un contexto en el que las tradicionales instituciones sociales de integración social, tales como el mercado laboral o el sistema educativo, parecen estar en crisis. Con el objetivo de reflexionar sobre la integración social de esta población, se propone este artículo analizar la práctica futbolística como posible mecanismo alternativo de integración social. En este sentido, se concluye que la práctica futbolística, tanto para menores como para adultos inmigrados, puede ser una potencial estrategia alternativa de integración social, en cuanto que pueda favorecer la adquisición de capital social y una formación intercultural. Sin embrago, la práctica futbolística es, también, ambivalente y limitada, tanto por los conflictos, problemas y procesos de exclusión social que se dan en el propio deporte, como por la incapacidad de esta institución de totalizar el complejo y multidimensional proceso de integración social.

\begin{abstract}
After a brief decline in migratory flows since the 2008 crisis, immigration has regained prominence, returning to the figures prior to the economic crisis. It is in this context that the debate on the social integration of foreign immigrants arises, in a context in which the traditional social institutions of social integration, such as the labour market or the education system, seem to be in crisis. With the aim of reflecting on the social integration of this population, this article proposes to analyse the practice of football as a possible alternative mechanism for social integration. In this sense, it is concluded that the practice of football, both for immigrant minors and adults, can be
\end{abstract}


a potential alternative strategy for social integration, insofar as it can favour the acquisition of social capital and intercultural training. However, the practice of football is also ambivalent and limited, both because of the conflicts, problems and processes of social exclusion that occur in sport itself, as well as because of the inability of this institution to totalise the complex and multidimensional process of social integration.

\section{Introducción}

España, tradicionalmente país de emigración, en el curso de unas pocas décadas se ha transformado en un importante país receptor de población de origen extranjero. Todo ello ha comportado transformaciones estructurales que han provocado cambios importantes a todos los niveles. En este contexto, la integración social de la población extranjera en España se convierte en un reto importante a gestionar, pues además del acomodo material de este colectivo, en cuanto a recursos socioeconómicos y status legal; se requiere favorecer su participación social e interacción dentro de la sociedad.

En tiempos de crisis, después de la del año 2008 y la de 2020 producto del COVID-19, las instituciones tradicionales, como es el caso de mercado laboral, aunque ya venían de antaño planteando problemas de inserción social (Zubero, 2006), están perdiendo la función social de la integración social de la población inmigrada'. Mucha población expulsada del mercado laboral por el declive del sector de la construcción; sumado al exceso de precariedad que obliga el propio mercado, particularmente, a la población inmigrada, hacen difícil dicha función social (Mahía, 2018). El sistema educativo, al que se le supone, igualmente, un poder de socialización y, por tanto, de integración social en la sociedad de destino, se ve, igualmente, con notorios problemas para afrontar los tiempos actuales caracterizados por la incorporación del alumnado extranjero en contextos de multiculturalidad. Los informes PISA datan dicha problemática, dibujando brechas significativas entre la población extranjera y nacional.

En este contexto, emerge una institución alternativa, quizás poco pensada y dirigida, explícitamente, para la función social de la integración, como es el deporte y, en específico, la práctica del fútbol. Reflexionando sobre las posibilidades de dicha alternativa institucional, se propone este artículo responder a diferentes cuestiones que suscita el binomio práctica deportiva, en este caso futbolística, e integración social: ¿Qué dimensiones sociales puede adquirir la práctica del fútbol para la población inmigrada en España? ¿Qué posibilidades y limitaciones pueden reproducirse en el contexto de la práctica futbolística para la población inmigrada residente en España? ¿Qué papel puede jugar la práctica futbolística a la hora de promocionar la integración intercultural? En definitiva, se trata de reflexionar sobre la función social que puede asumir la práctica futbolística en una sociedad cada vez más plural y multicultural.

Para la elaboración de este artículo, se parte primeramente, además de esta introducción, desde un estado de la cuestión en el que se hace referencia a la población inmigrada en cifras en España para, posteriormente, aproximarse a la dimensión social, deportiva y futbolística general y federada en España. Tras todo ello, se indaga en dos instituciones tradicionales de integración social como el empleo y la escuela, para, posteriormente, reflexionar sobre las posibilidades sociales y cohesivas del fútbol como práctica deportiva en un entorno multicultural como es el español.

\section{Población extranjera residente en España}

Desde finales de los años 90 y principios del 2000 España se convirtió en un importante país receptor de población de origen extranjero. Sin embargo, rápidamente, a partir de la crisis económica del año

\footnotetext{
${ }^{1}$ Con el objetivo de evitar confusiones innecesarias, en este artículo hablamos de personas inmigradas haciendo referencia a las personas que han vivido una experiencia migratoria de otro país a España.
} 
2007-2008, que golpeó fuertemente a las capas más débiles de la sociedad, esta población dejó de tener un crecimiento positivo. Las estadísticas del padrón colectivo (INE, 2021), registro municipal de toda la población residente en España, reflejan cómo la población extranjera desde la crisis económica no solo dejó de crecer, sino que, habiendo alcanzado en 2010 la cifra de 5.800.000 habitantes extranjeros, en 2017 tocó suelo, sufriendo un descenso de población habitante, situándose en la cifra de 4.572.807 de personas. Ahora bien, desde ese año, una vez comenzada la recuperación económica, la inmigración ha vuelto a crecer exponencialmente, pudiéndose hablar de una población de 5.407.822 de residentes empadronados a fecha de enero del 2021. Conscientes del posible impacto socioeconómico del COVID-19, habiendo ya conocido la importante influencia de la crisis financiera del 2008, veremos cómo influye en el comporta- miento migratorio de las personas extranjeras en España en los próximos años. ¿Volveremos a hablar de un retorno migratorio al país de origen producto de otra crisis económica? De momento, solo podemos hablar de que la inmigración ha crecido, situándose en el $11,4 \%$ de la población total.

Dicho esto, es pertinente hacer referencia a la composición nacional de la población extranjera residente en España: 4 de cada 10 personas extranjeras residentes son de origen sudamericano y marroquí, por lo que se hace notar la procedencia de estos orígenes nacionales, quienes han crecido a nivel de flujos migratorios de llegada en los últimos años. Destacan, asimismo, nacionalidades de países de la UE como Rumanía y, por otra parte, de Asía como China, aunque en continuo descenso desde hace unos años, producto, entre otras razones, del descenso de los flujos migratorios de dichos países.

\section{Gráfico 1. Flujo de inmigración del extranjero por procedencia y año (\%)}

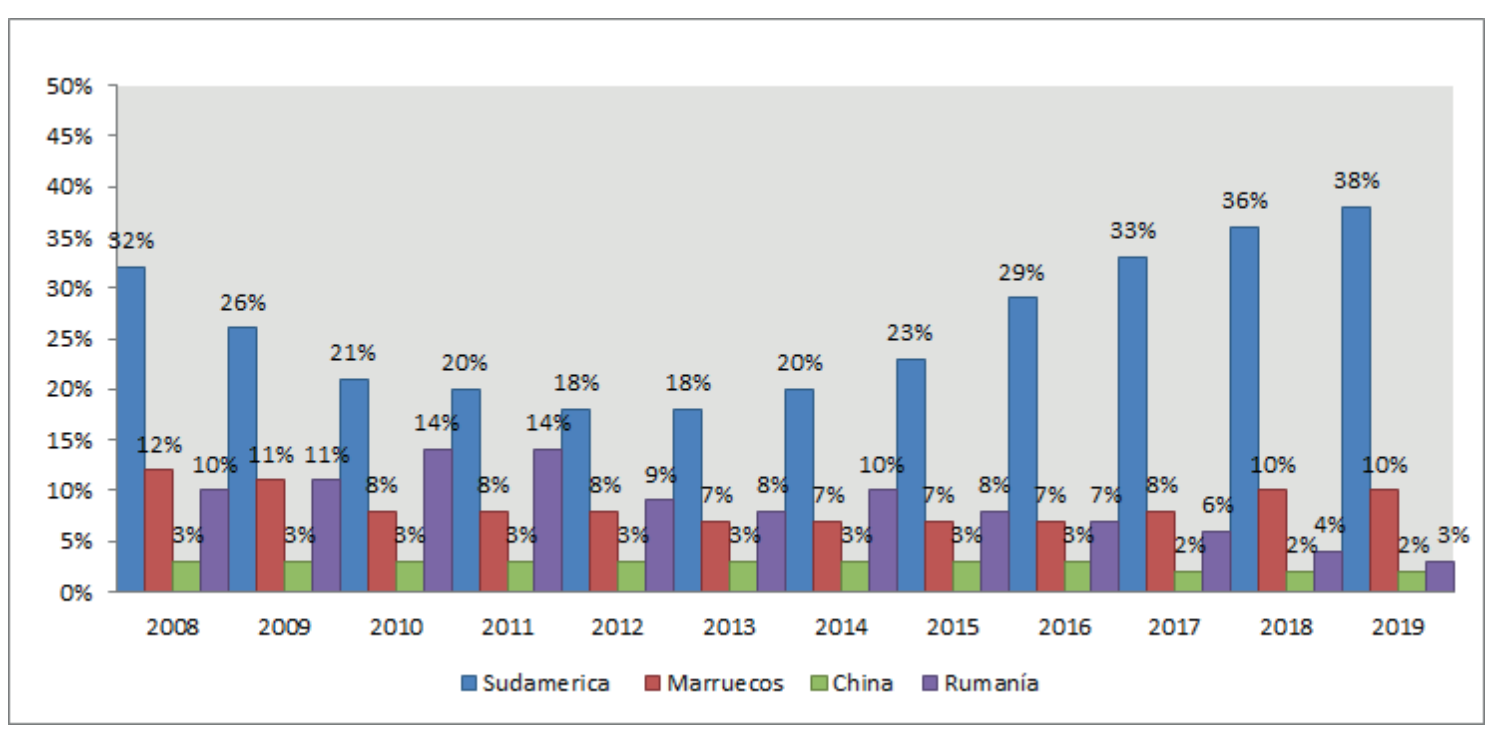

Fuente: Elaboración propia a partir de datos Estadística de Migraciones de INE (2019).

\section{Sobre la agencia de la integración: aproximación normativa y operativa de la integración}

Desde los años cincuenta, aunque mucho más tarde España, la sociedad europea percibe una extraordinaria alteración de su hábitat social y cultural, producto de las grandes migraciones de las antiguas colonias a los países europeos, tales como Francia, Alemania, Reino Unido y Países Bajos. Necesitados de mano de obra, muchos de estos países se aventuraron en lo que se acabó denominando equivocadamente los "guest workers" (Castles, 2000). Pues estos nuevos habitantes no eran, en absoluto, trabajadores invitados para un tiempo y con pasaporte de vuelta. La experiencia de Alemania con la inmigración turca o la francesa con la marroquí y la argelina son pruebas evidentes de ello. España, incorporándose a la carrera de la inmigración mucho más tarde, igualmente vería que la inmigración extranjera tenía intenciones 
de permanecer y que, detrás de todo, había proyecto migratorio para seguir viviendo en el país de destino. Todo esto acaba planteando nuevos debates y, sobre todo, nuevas incógnitas: ¿Cómo gestionar esta diversidad sobrevenida? Sobre esta cuestión, mucho se ha reflexionado, pudiéndose hablar de diferentes modelos normativos de gestión de la diversidad étnica. Todas ellas son aproximaciones teóricas y, muchas veces, normativas que, difícilmente, se corresponden con la pluralidad y la diversidad de formas de plantear la integración social, aunque, eso sí, tienen impacto en la concepción práctica de las políticas de integración social (Godenau et al. 2014).

Una de las grandes aproximaciones al proyecto de la integración de minorías es la política de la asimilación, practicada en Francia. La filosofía normativa de la asimilación defiende la incorporación paulatina a la cultura y a los valores hegemónicos de una sociedad (Gordon, 1964). Se exige abandonar en el espacio público todo tipo de manifestación simbólica o física de la cultura de origen, con el objetivo de incorporarse a un ideal laico de los valores de la república (Kennett, 2006). Sin pretensión de entrar a valorar el resultado de este modelo, en las últimas décadas han surgido modelos alternativos a éste, como el multiculturalismo, cuyo principal exponente es Charles Taylor (1993), quien defiende el reconocimiento político de todas las culturas, amparándose en la experiencia multicultural canadiense: la gestión de la diversidad se debe hacer asumiendo la expresión de las diferencias tanto en la dimensión privada como en la pública. sin embargo, este modelo no responde la pregunta de ¿Respetar todas las culturas necesariamente nos conduce a sociedades cohesionadas e integradas? Viendo que el multiculturalismo no responde a esta pregunta, surge el modelo de integración intercultural, afirmando la convivencia entre culturas a través del respeto, la comunicación, el aprendizaje mutuo y, sobre todo, el permanente diálogo horizontal entre culturas (Olivé, 1999).

Estos tres modelos citados no dejan de ser principios normativos, cuya implantación responde a una concepción de la integración, en tanto que teórica, desde una óptica lineal e ideológica. Al fin y al cabo, la integración es más compleja que todo eso: no responde a una finalidad concreta ni objetiva, sino que depende de una interacción dialógica entre la sociedad de acogida y las personas inmigradas (González, 2014) Por lo que hay que preguntarse cuáles son los factores que favorecen una empresa tan compleja como es la integración social: según Bosswick y Heckmann (2006), la integración social debería medirse en función de cuatro factores axiales: integración estructural, relacionada con la adquisición de status legal y derechos políticos, sociales y económicos en la sociedad de acogida; integración cultural, entendiendo que el conocimiento del idioma y la cultura local como una integración imprescindible; integración relacional, que debe ser satisfecha por la creación de redes sociales con la sociedad de destino; y, por último, la integración identitaria desde la óptica de la pertenencia y la identificación con la sociedad de destino y sus instituciones. Sobre estos cuatro factores pivota el trabajo de la integración social de las personas inmigradas, entendiendo que la integración es un proceso de permanente negociación (Godenau et al. 2014). Teniendo en cuenta estos factores, es pertinente analizar qué factores son los que pueden ser trabajados desde la práctica futbolística.

\section{Crisis del mercado laboral y sistema educativo ¿Emergencia de nuevas instituciones?}

A estas alturas huelga decir que la integración social es un concepto multidimensional en el que se integran, valga la redundancia, diferentes aspectos y factores de la realidad social. Dicho esto, no es óbice para afirmar la importancia de determinadas instituciones sociales, cuyo papel ha sido determinante para trabajar la cohesión social y, por ende, la integración social de las sociedades. Así, la institución familiar, laboral, educativa, recreativa, entre otras, han soportado la función de socializar y de integrar a las personas en la sociedad. Particularmente, la institución laboral y el sistema educativo en el caso de la población inmigrada (Pérez-Agote, 2016). Sin embargo, todas estas instituciones parecen sufrir la crisis de lo que se ha llamado la modernidad líquida (Bauman, 2002): pues donde había un importante poder institucional de integración, ahora nos encontramos con instituciones en pleno declive, al menos, tal como se han entendido tradicionalmente. Este declive de determinadas instituciones pone en jaque la integración de la población inmigrada, sobre todo si nos referimos a la crisis de las instituciones del mercado de trabajo o de la educación. Porque, tal como se ha observado anteriormente, la integración social, entre otros, opera en base a factores estructurales y relacionales, cuya incidencia, para el caso de las personas inmigradas, depende del empeño del mercado laboral y del sistema educativo. Pues este colectivo, en condiciones generales, al no tener garantizado un capital social sólido en la sociedad de acogida (familia y amistades), tiene que fiar su principal contacto a determinadas instituciones que puedan favorecer su arraigo social para integrarse en la sociedad. Sin embargo, el mercado laboral, al calor de las tendencias 
nacionales y globales, está en crisis: ya no es la institución de la estabilidad social ni del colchón socioeconómico que permitía a las personas ligar sus experiencias personales con sus trayectorias laborales en un puesto de trabajo (Zubero, 2006). El fenómeno de la globalización económica ha contribuido al debilitamiento de la fuerza laboral, por lo que el trabajo se convierte en inestable y, con ello, precariamente débil para las posibles aspiraciones de la población inmigrada. Ésta, a pesar de su juventud en relación a la población española y de tener, también, una población en edad activa mayor, sufre las tasas de paro más elevadas (Véase el gráfico 2 donde aparecen los datos de la Encuesta de Población Activa) y la precariedad laboral dibujada en contratos temporales y parciales (Mahía, 2018). En este contexto, el mer- cado laboral, lejos de fomentar positivamente una posible integración social, probablemente suponga un problema con efectos personales y psicológicos, ahondando en los problemas ya existentes (Senneth, 2005). Pero el impacto de este mercado laboral en crisis va más allá de la dificultad de absorción del excedente de mano de obra existente: otra de sus consecuencias es la pobreza y el aumento de las desigualdades, cuya viva imagen es la población inmigrada en España (Mahía, 2018 y 2021). Por eso, el economista Guy Standing (2013), atinadamente, definió a las personas inmigradas extranjeras como miembros destacados de la nueva subclase social: el precariado, cuyas características identifican un colectivo con altas tasas de paro y mucha precariedad laboral: trabajos temporales y contratos a tiempo parcial.

\section{Gráfico 2. Tasa de paro de población extranjera residente en España}

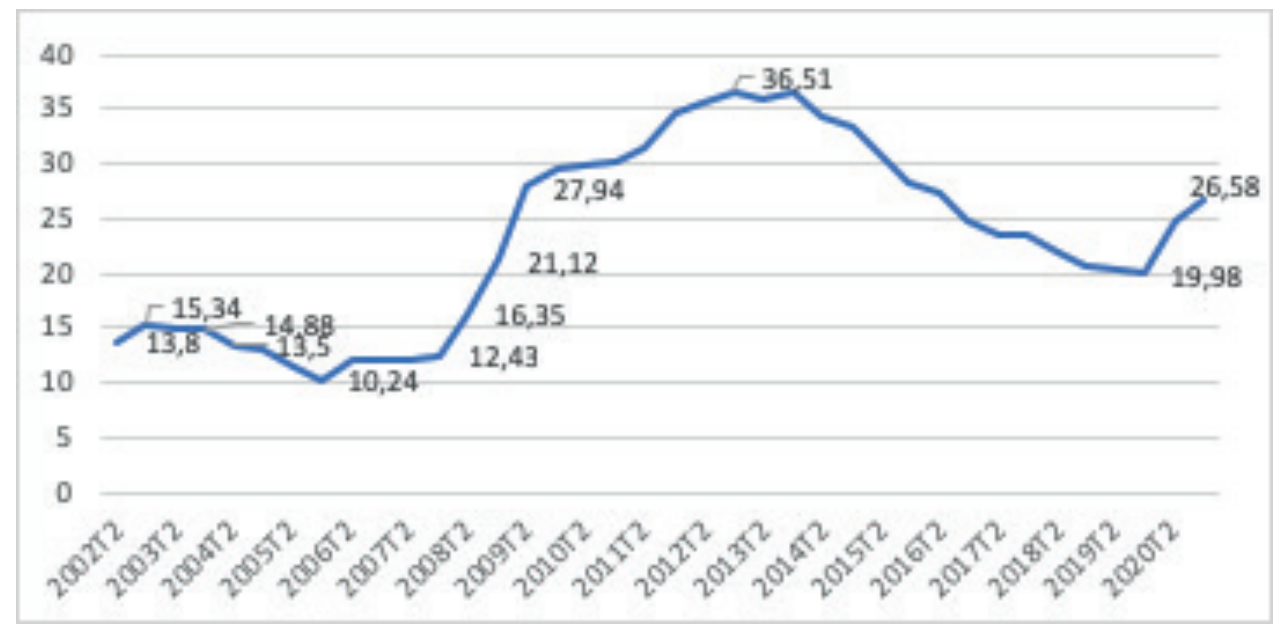

Fuente: Elaboración propia a partir de los datos de la Encuesta de Población Activa INE (2020)

Por otro lado, existiendo motivación especial por la educación como motor social de integración y gestión positiva de la diversidad, a decir verdad, esta institución tampoco está en condiciones para hacer frente a una población cada vez más heterogénea y multicultural (Dubet, 2010). La idea de la educación en la modernidad como institución moral con capacidad de generación de ciudadanía, tal como la entendía Durkheim (1975), ya no se sostiene. Dubet (2010) sociólogo francés, reflexiona sobre las transformaciones que ha sufrido este sistema educativo de la sociedad posmoderna. Por diversas causas, la institución educativa ya no es ese edificio influyente y jerárquico como se entendía en la sociedad moderna.
Su declive tiene que ver, según este sociólogo, con la pérdida de autoridad y legitimidad social como institución fundamental de transmisión del conocimiento. Dicho de otro modo, el monopolio que le correspondía antaño para transmitir moral, aprendizajes y conocimientos, hoy en día, se disputa con otras instituciones más informales.

La democratización en el acceso a la escuela o la multiculturalización de la misma, es decir, la apertura de una escuela donde puedan convivir diferentes etnias y orígenes, quizás forme parte de algunos de los elementos centrales para entender la crisis institucional del sistema educativo, cuya capacidad de gestión de la diversidad y, con ello, potenciar el conocimiento 
y la progresión educativa y, por tanto, social de determinados grupos sociales está siendo pobre. Las desigualdades en el entorno educativo son patentes y así lo atestiguan los Informes PISA: atendiendo al más reciente, es decir, al del año 2018 se puede afirmar que la brecha entre alumnado nacional y extranjero es tal que la separación es de 40 puntos en matemáticas o en ciencia, por ejemplo (Ministerio de Educación y Formación Profesional, 2019). Dicho problema va más allá de las aulas y están documentados sus orígenes en las condiciones socioeconómicas, orígenes, capital cultural y lingüístico de las familias inmigradas (Cebolla, 2013; Zinovyeva, Felgueroso y Vázquez, 2014). Para más inri, el propio Informe PISA resalta diferencias significativas entre el alumnado nacional y extranjero en cuanto al sentimiento de pertenencia a la escuela: el alumnado extranjero en España se siente menos identificado con la escuela que sus equivalentes nacionales. Quizás por ello España sea uno de los países con mayor polarización por origen a la hora de explicar las altas tasas de abandono escolar (Carrasco, Pamiés y Narciso, 2018). Por lo que, estos problemas educativos, lejos de resolver el gran desafío de la integración social, dan lugar a nuevas problemáticas que hacen más difícil un proyecto sólido de convivencia entre población local e inmigrada.

En este contexto, habida cuenta de que la población inmigrada extranjera se caracteriza por su juventud $^{2}$, adquiere relevancia un entorno de socialización y de interacción social que, siendo conscientes de su humilde poder institucional, al menos, comparadamente con el sistema educativo o el mercado de trabajo; puede ayudar a potenciar la integración social en una sociedad multicultural como la española. Por eso, en los últimos años es recurrente señalar académicamente el papel social que posee la práctica deportiva para favorecer la integración social, constituyendo un binomio interesante de estudiar (Moscoso et al. 2017; Piedra y Fernández-Gavira, 2012). De ello se hablará en los próximos apartados donde se reflexionará sobre las posibilidades y las limitaciones de la práctica futbolística, como práctica lúdica, pero, también, social, entre la población inmigrada.

\section{Dimensión social del deporte en España}

La práctica deportiva, tanto amateur como federada, se ha convertido en un tipo de ocio atractivo para la sociedad. En España, país con una gran tradición deportiva y, en especial, futbolística, se puede decir que el deporte es una práctica de inversión de tiempo libre. De acuerdo con la Encuesta de Hábitos Deportivos en España publicada en el año 2015, dirigida a población mayor de 15 años residente en España independientemente de su nacionalidad, casi la mitad de la población residente en España afirma practicar deporte por lo menos una vez a la semana $(46,2 \%)$, siendo una holgada mayoría de la población $(81,1 \%)$ quien afirma que, también, una vez a la semana practica deporte 0 , al menos, suele salir a hacer ejercicio andando. Todo ello hace notar que el deporte goza de buena salud en el seno de una sociedad que, por otra parte, acostumbra, también, a su atracción por el deporte televisivo y profesional. De hecho, 8 de cada 10 personas residentes en España, afirmaron, durante la encuesta citada, que siguieron espectáculos deportivos durante el último año.

Asimismo, en comparación con otras disciplinas deportivas, el fútbol es uno de los deportes más practicados y con mayor número de deportistas federados. Posicionándose como el deporte con más licencias en España, con un poco más de un millón de futbolistas federados, muy lejos del segundo deporte, el baloncesto, con un poco más de 350.000 personas federadas.

En referencia a la población residente extranjera, se percibe que el interés por la práctica del mismo, también, es notable. Al igual que la mitad de la población nacional, cuya práctica deportiva semanal es regular, el $41,5 \%$ de la población extranjera residente afirma que realiza deporte normalmente durante la semana. Un porcentaje que se eleva al $81,9 \%$ de los extranjeros que afirman realizar ejercicio, ya sea haciendo deporte, tal como se entiende, o saliendo a andar. Por lo que vemos, igualmente, el interés por el deporte también es importante, tal como sucede con la población local.

\section{Deporte y sociedad: ¿Un binomio siempre con efectos positivo?}

En este contexto, donde el deporte se ha consolidado a nivel social, la literatura científica ha desarrollado una extensa documentación de las oportunidades que supone la práctica deportiva para la sociedad (Checa et al., 2012; Pérez y Muñoz, 2018; Carter-Thuillier et al., 2017a). En general, se puede distinguir, por una parte, entre aquella literatura que expresa los beneficios sociales y socioeducativos del deporte (Maza, 2004; Cutforth y Puckett, 1999; Ruiz

\footnotetext{
${ }^{2}$ Casi 1 de cada 2 inmigrantes en España (46\%) tiene una edad inferior a los 34 años, según datos del INE (2021).
} 
Pérez et al., 2006; Carter-Thuillier et al., 2017b) y, por otra parte, aquella que, sin negar sus posibles beneficios, destaca factores y elementos que se dan en torno a la práctica deportiva y que pueden distorsionar el trabajo social y educativo (Heinemann, 2002; Piedra y Fernández, 2012; Contreras, 2002; Contreras et al., 2008; Santos-Ortega, 2019).

Atendiendo a diferentes investigaciones, se puede decir que la práctica deportiva emerge como una institución social con recursos y herramientas integradoras a nivel social, en cuanto que posibilita la extensión del capital social y la ampliación de redes interpersonales (Maza, 2004; Santos y Balibrea, 2013; Pérez y Muñoz, 2018). Sumado a ello, el deporte también se analiza como una institución de trabajo socioeducativo, por el propio espíritu del deporte y por la labor que se pueda emprender en el seno de la práctica deportiva. Dimensiones como el compañerismo, la cooperación, la colaboración, el esfuerzo, el respeto, la autonomía y el empoderamiento, entre otras, pueden ser trabajados positivamente durante la práctica deportiva (Soler et al., 2017; Pardo y García-Arjona, 2011). De este modo, según Checa y otros (2012) la práctica deportiva puede operar a dos niveles cuando nos referimos a la integración social: por un lado, potenciando el capital personal y humano, el deporte puede contribuir al bienestar físico, personal y emocional de la persona, haciéndole crecer en autoestima y confianza; pero, por otro lado, también, puede beneficiar a la producción de capital social, ampliando, con ello, las interacciones sociales, construyendo identidades y contribuyendo a la vida de la comunidad.

Teniendo en cuenta las ventajas de la práctica deportiva, cada vez más investigaciones relacionan el deporte con el trabajo de integración social de las poblaciones vulnerables, entre las cuales se encuentra la población inmigrada (Checa et al., 2012; Sánchez, 2010). Dados sus potenciales recursos en cuanto a extensión de capital social como a sus beneficios socioeducativos, se argumenta que la práctica deportiva puede trabajar la dimensión inclusiva de aquellos colectivos que se encuentran con problemas sociales y económicos. Al tratarse de un deporte con reglas universales y no predeterminadas por un lenguaje simbólico, se considera que puede facilitar el contacto e interacción social de las poblaciones vulnerables con la sociedad. En efecto, en el caso de las poblaciones inmigradas de origen extranjero, la práctica deportiva puede facilitar una serie de ventajas: construcción de redes sociales interétnicas, ampliar las redes de colaboración y ayuda, aprendizaje del idioma y estimular una relación intercultural, etc. (Afable-Munzuz, 2010). Sobre este último punto, diferentes investigaciones concluyen que el deporte puede ser un activador de relaciones y aprendizajes interculturales (Giess-Stüber y Grimiminger, 2008; Contreras, 2002; Llopis Goig, 2009 y 2010), dado que, como el deporte se sostiene a través de reglas supraculturales, puede facilitar la comprensión del otro y la generación de canales de interacción intercultural. Con ello, se pueden construir aprendizajes mutuos sobre las diferencias sociales y culturales existentes, minimizando el impacto de las desconfianzas interculturales. En este contexto, se considera que la práctica deportiva puede favorecer el entendimiento mutuo, la confianza, y, a través de la mismo, romper con los prejuicios y estereotipos culturales (Checa et al., 2012).

Sin embargo, a pesar de esta extensa literatura sobre las ventajas de la práctica deportiva, diferentes investigaciones académicas señalan las limitaciones de la misma, ya sea por no alcanzar, precisamente, a toda la población vulnerable (Fraguela et al., 2018; Checa et al., 2012; Piedra y Fernández, 2012), o por el simple hecho de que el deporte per se no produce efectos positivos a nivel social, psicológico y educativo sin un acompañamiento exhaustivo de decisiones y medidas de trabajo (Arjona et al., 2016; Rodrigo y García-Arjona, 2011). En este sentido, parte de la literatura académica alerta del riesgo de la práctica deportiva sin una hoja de ruta precisa de trabajo para la integración social de población vulnerable, dado que el deporte puede ser terreno abonado para la reproducción de problemas existentes en la sociedad, es decir procesos de exclusión de diferente índole (Checa et al., 2012).

Por tanto, al margen de los potenciales beneficios ya referidos de la práctica deportiva, estas investigaciones señalan las dificultades que limitan la acción positiva del trabajo social y educativo del deporte: más allá de la práctica deportiva, Contreras (2002) no percibe una transferencia automática y directa de los beneficios conseguidos a la sociedad, distinguiendo, así, lo que sucede en el terreno de juego y la vida social externa al deporte; Pfister (2004) afirma que el mismo deporte, aunque se rija por reglas universales, está condicionado por una determinada concepción normativa del individuo, del cuerpo y del movimiento, por lo que choca con las diferencias culturales, limitando el trabajo intercultural sobre todo con las poblaciones inmigradas; Coincidiendo con esto último, Barker et al (2013) sostiene que habitualmente se considera al deporte como una práctica neutra a nivel cultural, cuando lleva implícito un lenguaje cultural y simbólico hegemónico, por lo que dificulta una fácil inserción social de las poblaciones inmigradas. Es más, la práctica deportiva no está al alcance de todas las personas, dados los procesos de exclusión que se dan previamente por razones de género, edad, clase social, origen étnico etc., provocando que el deporte 
no pueda llegar, precisamente, a aquellas poblaciones más vulnerables (Piedra y Fernández, 2012). Las investigaciones de Arjona et al. (2012) y de Checa et al. (2012) demuestran que la inserción deportiva de determinados colectivos, como el inmigrado, es reducida en comparación con la población nacional, ya sea por falta de tiempo de ocio, por estar centrados en cuestiones más elementales como el disponer de un trabajo, o el simple hecho de dedicarse a las tareas familiares y de cuidados, como sucede en el caso de las mujeres (Piedra y Fernández, 2012). Por otro lado, la práctica del deporte, al ser tan mediatizada y convertida en una industria televisiva, igualmente puede condicionar negativamente el trabajo integrador del deporte, pues reproduce prejuicios, estereotipos y malas prácticas observadas en el deporte de elite y que tienen traslación en el deporte educativo y amateur (Contreras et al., 2008); en este sentido, Molina (2010), también, alerta de la ambivalencia del deporte, porque puede ser terreno propicio para la generación de conflicto y de problemas culturales.

Teniendo en cuenta todo esto, diferentes investigaciones señalan que, si el deporte no se trabaja desde una óptica exclusivamente integradora y facilitadora de adquisición de aprendizaje de valores, puede dejar de tener los efectos positivos deseados (Arjona et al., 2016). Investigaciones realizadas en entornos educativos destacan que la función del educador o del monitor deportivo es determinante a la hora de trabajar la integración social de poblaciones de origen inmigrado (Carter-Thuillier et al., 2017; Arjona et al., 2016). Para ello, se requiere de un diseño y una planificación determinada, que ponga en el centro de sus objetivos el trabajo de la integración social por encima de la competición. Particularmente resulta necesaria la existencia de un diseño especifico cuando se trabaja con población inmigrada, pues se requiere de un trabajo previo a nivel de formación intercultural para que se pueda hablar de una práctica deportiva con beneficios sociales y educativos (Arjona et al., 2016; Checa et al., 2012). De lo contrario, el deporte per se no puede ni corregir las desigualdades existentes ni favorecer la comunicación intercultural. Más bien, puede ahondar en las diferencias y ser un espacio abonado al conflicto.

\section{El papel del Fútbol federado: Capital Social y redes de solidaridad}

A pesar de ser una práctica reducida a la población joven en general, sobre todo, si nos referimos al fútbol federado; a decir verdad, este deporte puede representar un mecanismo que posee la sociedad para favorecer el encuentro y la convivencia social. La práctica futbolística, lejos de delimitarse en los clásicos objetivos de lo lúdico, como hemos visto, puede llegar a ser una referencia como institución social con potencial facultad de acometer la tarea de la integración social de las personas inmigradas. Su capacidad de generación de capital social y de redes de solidaridad (Pérez y Muñoz, 2018), pueden apuntar a una práctica favorable a la integración social, al menos relacionada a la vertiente de la integración relacional, cultural e, incluso, identitaria. Activando, con ello, beneficios tanto individuales como de capital social (Henry, 2005a y 2005b).

Entendiendo el concepto de capital social, según uno de sus máximos exponentes Pierre Bourdieu (1986), como un agregado de recursos sociales y de redes relacionales del que dispone un individuo; es pertinente proponer los beneficios de la inserción deportiva de la población inmigrada. Pues si por algo se caracteriza esta población, entre otras problemáticas, es por la debilidad de sus redes sociales y, por ende, de su capital social, imprescindible a la hora de potenciar el tipo de integración social, antes mencionado, relacional. Habida cuenta de que el fútbol es una práctica arraigada e institucionalizada, tal como se ve en las estadísticas del deporte federado en España, la práctica futbolística puede adquirir un valor notable: conformar las primeras redes sociales en el caso de la población inmigrada con poco tiempo de residencia en España. Dichos vínculos relacionales pueden ser, también, potenciales vínculos de colaboración y de solidaridad tanto para buscar trabajo como para apoyos puntuales. Dicho de otro modo, la práctica del fútbol puede ser un incentivo estratégico de inversión a la ahora de producir y acumular capital social puente, es decir la conformación de redes sociales con la sociedad de acogida.

La expresión social de la práctica futbolística es, asimismo, un móvil para empezar a integrar socialmente a la población inmigrada en el seno de la propia sociedad y no desde fuera, tal como se hace, muchas veces, en el sistema educativo separando al alumnado nacional del inmigrado, con el fin de trabajar separadamente aspectos idiomáticos, para posteriormente, una vez adquiridos éstos, incorporarle al aula (Etxeberría y Elosegui, 2010). Porque la práctica del fútbol consiste en un lenguaje universal que no demanda, a priori, tanto como el sistema educativo o el laboral, de capacidades simbólicas y culturales propias del país de destino. De este modo, poder trabajar la integración social desde dentro a través de la práctica futbolística y no separadamente de la sociedad, es un valor añadido para potenciar la integración relacional con la población local, garantizando que, 
desde un inicio, exista una interacción social positiva bajo principios lúdicos.

A este respecto, muy pertinente la utilización que hace del concepto de capital social y campo social de Bourdieu la socióloga Sagarsasu (2013), quien, aplicando dicha teoría de capital social, sostiene que el deporte puede facilitar la incorporación social de la población inmigrada, dado que forma parte de un campo social ajeno de los desequilibrios o desigualdades que, precisamente, hacen difícil la integración social de los personas inmigradas en otros campos sociales. Empleando la propuesta de esta autora, es pertinente afirmar que existen diferentes campos sociales en la sociedad donde se integran las personas, en base a los desiguales niveles de capital que se poseen. Por lo que, en función del nivel de capital disponible, podemos hablar de un proceso de integración positivo o no. En este caso, la población inmigrada, cuando llega a la sociedad de destino, debe participar en distintos campos sociales, pero, por lo general, con un capital disponible bastante limitado. Todo ello, puede acabar siendo problemático para el contacto social con la sociedad de destino y, potencialmente, fuente de desigualdad. Sin embargo, la ventaja de la práctica deportiva cuyas reglas son universales, radica en que tales desigualdades o brechas, a la hora de poner en juego los diferentes capitales de los que se dispone, se reducen. Precisamente, porque se trata de un deporte universal y de una práctica física y no tanto cultural o lingüística, puede favorecer la posibilidad de la integración social, y contribuir, asimismo, a la acumulación agregada de más capital social y de otros recursos sociales o de otra índole (Molina, 2010).

\section{El fútbol y las posibilidades de la interculturalidad}

Sabemos que las sociedades caracterizadas por la recepción y acogida de población de origen inmigrante se enfrentan a posibles problemas sociales como el debilitamiento de su confianza social (Putnam, 2007), dado que la permanencia en un espacio social con múltiples fuentes de diferenciación identitaria, puede dar lugar a un debilitamiento del capital social ${ }^{3}$ de una sociedad, de tal modo que puede ir en detrimento de su unidad y cohesión social. En este contexto de diferencias, la práctica del fútbol puede erigirse como medio de promoción del encuentro intercultural y, con ello, dirigirse hacia la activación de la confianza social (Pérez y Muñoz, 2018), producto del contacto social entre grupos de población interétnicos.

En ciencias sociales se citan dos teorías que han pretendido aproximarse teóricamente a la convivencia social entre personas inmigradas y nativas (Zubero, 2010): siendo una de ellas la que identifica el contacto social como fuente de conflicto, producto de la escasez de recursos y de la necesidad de competir por los mismos. Se trata de la teoría del conflicto que rechaza, asimismo, la hipótesis de contacto que, a diferencia de la primera, pertinentemente, afirma que el conflicto y el rechazo a las personas inmigradas puede ser producto, precisamente, de la inexistencia de medios para el contacto social. De tal modo que eliminando las barreras invisibles que obstaculizan el contacto social, se derribaran los conflictos y la desconfianza hacia las personas inmigradas. En efecto, el fútbol, en este contexto, ofrece la ventaja de ser un activo que genera atracción social universalmente, producto de su arraigo en todo el mundo. Por ello, resulta extraordinario el rol que puede desempeñar la práctica futbolística acercando a las personas independientemente de su cultura o religión, contribuyendo a la producción de aprendizajes a nivel intercultural.

Precisamente, por todo ello, la práctica del fútbol ha sido denominada por muchos estudiosos de la función del deporte como una práctica de integración intercultural (Durán, 2009; Kennet, 2005; Molina, 2010), dado que, produciéndose en un contexto lúdi$\mathrm{co}$, puede despertar sentimientos de comunidad, de identidad y de pertenencia independientemente de las diferencias culturales, sociales o religiosas, contribuyendo a normalizar las diferencias culturales en pro de un beneficio superior que es la práctica deportiva. Dicho valor positivo hace de la práctica futbolística un deporte, ante todo, apto para desarrollar contenidos educativos potenciadores de una educación intercultural en valores. Una educación que ayude a generar vínculos socioculturales, distinguidos por la comprensión del diferente y la cooperación humana con el considerado otro.

Ahora bien, teniendo en cuenta la literatura académica sobre la práctica deportiva, es necesario ser prudentes ante tal empresa intercultural: el fútbol como práctica deportiva puede proporcionar cana-

\footnotetext{
${ }^{3}$ Putnam (2007) utiliza el concepto de capital social, a diferencia de Bourdieu y otros sociólogos, para referirse a aquella variable que mide el grado de confianza social que existe en una sociedad. De tal modo que sociedades con alto capital social son sociedades cohesionadas mientras que aquellas con bajo capital social son sociedades con altos niveles de desconfianza social y poca cohesión social.
} 
les de comunicación intercultural, sin embargo, para ello, se requiere el compromiso de todas las partes involucradas para garantizar dicha comunicación intercultural, teniendo que haber, por encima de todo, una correcta organización que haga de la práctica deportiva un medio de integración intercultural. De lo contrario, se corre el riesgo de que se convierta en una práctica física y lúdica y, especialmente preocupante, en un espacio de conflicto de intereses más allá de los objetivos de integración social.

Sumado a todo lo comentado, es importante hacer mención al necesario trabajo de coordinación y organización de la práctica deportiva, dado que, sin ella, no se pueden desarrollar itinerarios interculturales donde, también, la voz de las personas inmigradas participe del diseño y del modo de gestión y organización de vida social que acompaña a la práctica deportiva. El riesgo de no hacerlo conlleva la posible desmotivación y desinterés de las personas inmigradas a la hora de participar en la práctica futbolística o, sencillamente, distanciarse del grupo mayoritario conformando grupos pequeños endogrupales. Sentirse involucrados y parte activa en el desarrollo de la práctica deportiva, puede ayudar a empoderar socialmente a las personas inmigradas, además de aumentar su autoestima.

\section{El fútbol y sus limitaciones: la ambivalencia del fútbol y el riesgo de subestimar la multidimensionalidad de la integración}

Sería de escaso rigor desdeñar las limitaciones que sufre la práctica futbolística, tanto por su limitado campo de acción en la múltiple tarea de la integración social como por las problemáticas que se pueden reproducir en el seno de este deporte de masas. En efecto, el fútbol, como cualquier práctica social, puede resultar sumamente ambivalente (Elling, DE Knop y Knoppers, 2001), en el sentido de estar dispuesto a lo mejor de las funciones sociales de la integración de diferentes colectivos; pero ser, asimismo, reproductor de problemas, procesos y dinámicas de exclusión social, que puedan perjudicar severamente la situación social de las personas inmigradas. De acuerdo con las profesoras Ispizua, Soler y Mendoza (2017), el deporte puede ser una herramienta tan útil como peligrosa: útil porque en las fronteras interiores del deporte se pueden reproducir muchos valores y prácticas que ayuden a la integración social: como, por ejemplo, el compañerismo, sentimiento de unidad, pertenencia, confianza social, compromiso o responsabilidad, tal como hemos descrito en anteriores apartados; sin embargo, resulta necesario tener en cuenta que el deporte, hoy en día, puede ser fiel reflejo de muchas realidades que entran en tensión, cuando no en colisión directa, con proyectos de inclusión social: hablamos de la discriminación y exclusión que se pueden reproducir dentro del deporte por razones de xenofobia, homofobia, o clasicismo, etc. (Soler, Ispizua, \& Mendoza, 2017).

El fútbol, siendo uno de los deportes más seguidos en el mundo y con holgada capacidad de movilización social, mueve muchas pasiones y emociones humanas. Por lo que su carácter ambivalente le convierte en una práctica de riesgo cuando las emociones dividen y separan entre las personas. Sin duda, el fútbol, como práctica deportiva, contribuye a la construcción y a la significación de la identidad social, produciendo una ingente cantidad de identificaciones y símbolos sociales (Domínguez, 2009). El posible perjuicio de dichas identidades, conformadas por las identificaciones sociales, muchas veces, reside en su carácter segregador del nosotros frente al ellos (Tajfel, 1984). Por lo que el riesgo reside en que la práctica futbolística se alimente de determinadas actitudes y comportamientos divisivos y excluyentes, provocadores de violencia física y verbal (Henry, 2007). No hace falta más que echar un ojo al fútbol profesional para observar las expresiones nacionalistas excluyentes, racistas y xenófobas. El caso de Iñaki Williams ${ }^{4}$, futbolista de origen africano del Athletic Club de Bilbao en Barcelona ante el Espanyol o el de Samuel Eto' $0^{5}$ en el campo de fútbol de la Romareda ante el Real Zaragoza, forman parte de dichas expresiones sociales que deben hacernos reflexionar sobre las grandes limitaciones que todavía persisten en la práctica futbolística, que, muchas veces, resulta instrumentalizadas para otros objetivos, como pueden ser fines políticos y nacionalistas (Kennet, 2005). El problema de todo esto, es que la práctica futbolística, aunque sea amateur o con fines socioeducativos, también se puede alimentar referentemente de estas situaciones limitantes del trabajo integrador y educativo. En efecto, el fútbol de elite produce grupos de referencia, de tal modo que todas las problemáticas segregadoras y excluyentes pueden tener efectos sociales en las personas que practican el deporte

\footnotetext{
${ }^{4}$ https://www.europapress.es/catalunya/noticia-fiscalia-denuncia-dos-aficionados-espanyol-insultos-racistas-williams-rcde-staduium-20201116112025.html.

${ }^{5}$ https://www.elmundo.es/elmundodeporte/2006/02/26/futbol/1140910900.html.
} 
no profesional, por lo que ello, puede llegar a poner en peligro el trabajo de integración intercultural en el seno de la práctica deportiva.

Por eso, es imprescindible no pasar por alto la idea de que la práctica futbolística, no garantiza per se que sea un espacio propicio para la existencia de una integración intercultural, dado que, para ello, es necesario desarrollar una comunicación intercultural en el seno de la práctica deportiva, siendo necesario la voluntad positiva de todas las partes intervinientes para que pueda trabajarse dicho modo de integración social a nivel dialógico.

Llegados a este punto, cabe, también, hacer referencia a otra de las grandes limitaciones de la agencia integradora del fútbol. Si bien es cierto que, tal como se ha argumentado en este artículo, la práctica del fútbol ofrece condiciones alternativas de inserción e integración social; igualmente, resulta pertinente identificar las limitaciones de ésta, a saber: habida cuenta de que la consecución de la integración social es compleja y dependiente de muchos factores, la práctica del fútbol resulta a todas luces insuficiente para hacer frente a la multidimensional tarea de la integración social. Porque, tal como afirma Arango (2012), la integración social es, también, acceso a derechos como los de residencia legales, de vivienda, de condiciones de vida dignas, etc. Por lo que, la práctica del fútbol, aunque favorezca la producción de capital social y de redes de contacto y de solidaridad, no puede garantizar por si sola el acceso a los derechos anteriormente citados. De tal modo que como dicen estas investigadoras:

El deporte orientado a los colectivos en riesgo de exclusión social, por ejemplo, aunque se utilice de forma correcta, si bien puede mejorar las condiciones de vida de dichos colectivos y es capaz de reducir su nivel de vulnerabilidad, no puede resolver el conjunto de problemas estructurales que generan desigualdad ni cubrir las necesidades (Soler, Ispizua, \& Mendoza, 2017, pág. 153)

En este contexto, el efecto alternativo de la práctica del fútbol tiene muchos ingredientes positivos para la integración social, pero, sin duda, la integración de las personas inmigradas va más allá (Domínguez, 2009). Tenerlo en cuenta es sumamente importante, pues de lo contrario se puede caer en el riesgo de sobredimensionar el papel de la integración individual y relacional, subestimando el carácter estructural de la integración social de las personas inmigradas (Haudenhuyse y Theeboom, 2015).

\section{Conclusiones}

En este artículo nos hemos propuesto valorar las posibilidades y limitaciones que presenta el fútbol como práctica deportiva a la hora de integrar socialmente. Siendo conscientes de la capacidad de movilización social de este deporte, así como de su atractivo a nivel de práctica deportiva; puede contribuir a desarrollo el trabajo de integración social de aquellas poblaciones inmigradas que, por sus contextos vitales, pueden necesitar de estos espacios sociales para integrarse. En efecto, el fútbol puede ayudarles a producir capital social y redes de cooperación y de solidaridad en la sociedad de acogida. Por eso, se ha afirmado que la práctica del fútbol puede ayudar a construir vínculos sociales y humanos más allá de las diferencias culturales, étnicas o religiosas que caracterizan a nuestras sociedades multiculturales. Teniendo en cuenta este valor añadido, se podrá estimular el contacto y la confianza intercultural.

Sin embargo, el fútbol, como práctica deportiva y social, puede ser sumamente ambivalente: pues, puede estar dirigido hacía buenas prácticas de inclusión e integración, pero, también, hacía la exclusión y la segregación social. Como ya se ha dicho, el fútbol mueve muchas emociones y produce significados, símbolos e identidades, por lo que, fácilmente, se puede caer en el terreno de la exclusión, la discriminación social o la exacerbación de las diferencias a nivel identitario. Particularmente, la práctica futbolística es más sensible a estos problemas cuando no haya itinerarios formativos específicamente dirigidos al trabajo de la integración social. En este sentido, la práctica futbolística, sin una regulación socioeducativa específica, puede dar lugar a la expresión de muchas emociones e identidades divisivas. Por lo que no hay que perder de vista estos potenciales problemas.

Dicho esto, las limitaciones del fútbol no se quedan en esta dimensión ambivalente: pues aun siendo un posible valor añadido para potenciar la integración social, es pertinente afirmar que su agencia es limitada, pues la integración social va más allá de la generación de redes sociales, sentimientos de pertenencia y una educación intercultural, tal como puede suceder en el fútbol. La integración social, desde una perspectiva estructural, también, es acceder a derechos ya sean civiles, de vivienda o a un trabajo digno. Dimensiones sociales que no puede garantizar la práctica del fútbol.

Por todo ello, no se puede dudar de las posibilidades alternativas que ofrece la práctica futbolística en contextos de pluralidad cultural y social. Ahora bien, no se debe menospreciar el carácter ambivalente 
del deporte, sobre todo, la práctica futbolística que mueve muchas emociones. Pues teniendo en cuenta las limitaciones del fútbol, tanto por su humilde agencia integradora como, igualmente, por los múltiples problemas que pueden reproducirse en su seno; se podrá trabajar la dimensión integradora con mayor conocimiento y mejores resultados.

\section{Referencias}

Afable-Munzuz, A., Ponce, N., Rodríguez, M. y Pérez-Stable, E. 2010. "Immigrant generation and physical activity among Mexican, Chinese and Filipino adults in the U.S". Social Science and Medicine, 70, 1997-2005.

Arjona, Ángeles, Checa, J. C, Pardo, R. P., García, N. G. 2016. "Educación física y deporte: ¿Instrumentos de integración de inmigrados?" Revista de Ciencias sociales, 22(3): 10-21.

Barker, Dean, Barker-Ruchti, Natalie, Gerber, Markus, Gerlach, Erin, Sattler, Simone, Bergman, Max, y Púhse Uwe. 2013. "Swiss youths, migration and integrative sport: A critical constructive reading of popular discourse". Europe Journal for Sport and Society, 10(2):143-160.

Bauman, Zygmunt. 2002. Modernidad Líquida. S.L. México: Fondo de cultura económica España.

Bosswick, Wolfgang y Heckmann, Friedrich. 2006. "Integration of migrants: Contribution of local and regional authorities". European Foundation for the Improvement of Living and Working Conditions.

Bourdieu, Pierre. (s.d.). "Le capital social: notes provisoires", en Actes de la Recherche en Sciences Sociales 31:2-3.

CanalULL. "Conferencia de Joaquín Arango Vila-Belda: "De la inmigración a la integración" Video de YouTube, 1:27,06. Publicado el 28 de febrero de 2012 https://www.youtube.com/watch?v=5Rjn-7VqTLM

Carrasco, Silvia; Pàmies, Jordi; Narciso, Laia. 2018. "Abandono escolar prematuro y alumnado de origen extranjero en España: ¿un problema invisible?" Anuario CIDOB de la Inmigración, [en línea], 2018: 212-36, https://doi.org/10.24241/AnuarioCIDOBInmi.2018.212

Castles, Stephen. 2000. Ethnicity and Globalization. London: Sage publications.

Cebolla, Héctor. 2013. Inmigración y Educación: Los problemas tempranos de rendimiento escolar de los hijos de los inmigrantes (págs. 165-183). In: J. Arango, D. Moy, \& J. Oliver, Inmigración y Emigración: Mitos y realidades. Madrid: Anuario de la inmigración en España.

Checa, Juan Carlos, Garrido; Arjona, Angeles; Pardo, Rodrigo. y García-Arjona, Noemí. 2012. “Deporte e integración. Variables que intervienen en el contacto cultural de los jóvenes inmigrados en España". Revista de psicología del deporte, 21(2): 233-242.

Contreras, Onofre. 2002. Perspectiva intercultural de la Educación Física. En Multiculturalismo y Educación Física, editado por T. Lleixà, 9-45. Barcelona: Paidotribo.

contreras, Onofre, Pastor, Juan Carlos, \& González, Sixto. 2008. "La influencia de los deportistas de élite en las actitudes y estereotipos racistas". Tandem, 28, 27-38.

Cutforth, Nicholas y Puckett, Karen. 1999. "An Investigation into the Organization, Challenges, and Impact of an Urban Apprentice Teacher Program". The Urban Review. 31,(2): 153-172.

De las Heras, Ainhoa. 2020. "45.000 niños sin deporte escolar". El Correo, 3 de septiembre de 2020. 45.000 niños sin deporte escolar | El Correo

Domínguez, Sara. "Deporte e inmigración: el deporte como elemento de aculturación de los ecuatorianos en la ciudad de Madrid". (Tesis doctoral, Universidad Politécnica de Madrid, 2009). http://oa.upm. es/4834/1/SARA_DOMINGUEZ_MARCO.pdf

Dubet, François. 2010. "Crisis de la transmisión y declive de la institución". Política y Sociedad, 47 (2): 15-25.

Durán, Luis Javier. 2009. Actividad física, deporte e inmigración. El reto de la interculturalidad. Madrid: Dirección General de Deportes de la Comunidad de Madrid.

Durkheim, Emile. 1975. Educación y Sociología. Barcelona: Península.

Elling, Agness; De Knop, Paul; Knoppers, Annelies. 2001. "The social integrative meaning of sport: A critical and comparative analysis of policy and practice in the Netherland". Sociology of sport journal, 18 (4): 414-434.

El Mundo. "Eto'o amenaza con dejar el partido por insultos racistas" El Mundo, 26 de febrero de 2006. https://www.elmundo.es/elmundodeporte/2006/02/26/futbol/1140910900.html

Etxeberría, Félix. y Elosegui, Kristina. 2010. "Integración del alumnado inmigrante: obstáculos y propuestas". Revista Española de Educación Comparada, 16: 235-263

Europa Press. "Fiscalía denuncia a dos aficionados del Espanyol por insultos racistas a Williams en el RCDE Staduium". Europa Press, 16 de noviembre de 2020. https://www.europapress.es/ catalunya/noticia-fiscalia-denuncia-dos-aficionados-espanyol-insultos-racistas-williams-rcde-staduium-20201116112025.html

Fernández-Gavira, Jesús; Piedra de la Cuadra, Joaquín y Pires, Francisco. 2013. “Deporte e Integración Social: Oferta y Demanda Deportiva de los Jóvenes 
de la Zona sur de Sevilla". EmasF: Revista Digital de Educación Física, vol. 24: 31-34.

Fraguela, Raúl, De-Juanas, Ángel y Franco, Ricardo. 2018. "Ocio deportivo en jóvenes potencialmente vulnerables: beneficios percibidos y organización de la práctica". SIPS - Pedagogía social. revista interuniversitaria, 31, 49-58

G. Gil, Aimara. "Un Francia multicultural con raíces en Argelia, Congo..." $A S, 10$ de julio 2018. https://as.com/futbol/2018/07/10/mundial/1531182423_535338.html

Giess-Stüber, P. y Grimiminger, E. 2008. "Reflexive interculturality as a development for schools and school sports". En Sport-Integration-Europe. Widening horizons in intercultural education, editado por P. Giess-Stüber y D. Blecking, 297-303. Baltmasnnsweiler: Schneider.

Godenau, Dirk; Rinken, Sebastián; Martínez de Lizarrondo Artola, Antidio y Moreno Gorka. 2014. La integración de los inmigrantes en España: Una propuesta de medición a escala regional. Observatorio Permanente de la Inmigración.

González, Yolanda. 2014. "Los procesos de integración de personas inmigrantes: límites y nuevas aportaciones para un estudio más integral". Athenea Digital, 195-220.

Gordon, Milton. 1964. Assimilation in American Life: The Role of Race, Religion, and National Origins. USA: OUP

Haudenhuyse, Reinhard y Theeboom, Marc. 2015. "Sport for Social Inclusion: Critical Analyses and Future Challenges". Social inclusion, vol. 3, n. 3: 1-4.

Heinemann, Klaus. 2002. "Deporte para inmigrantes: ¿instrumento de integración?". Apunts. Educación física y deportes, 2, (6): 24-35.

Henry, Ian Paul. 2005a. Playing along: sport as means for social integration. En $2^{\mathrm{a}}$ conferencia de Magglingen sobre deporte y desarrollo (4-6 de diciembre 2005, Magglingen, Suiza).

Henry, lan Paul. 2005b. Sport and multiculturalism: an european Perspective (Online articule). Barcelona: Centre d'Estudis Olimpics UAB.

Henry, lan Paul. 2007. Sport and social integration strategies: the use of sport for social integration among refugee and ayslum seekers. Jornada, actividad física, deporte e inmigración. El reto de la interculturalidad (Madrid, 26 y 27 de octubre de 2007).

INE (2019). «Estadística de Migraciones». Recuperado de https://uww.ine.es/dyngs/INEbase/es/operacion.htm?c=Estadistica_C\&cid=1254736177000\&menu=ultiDatos\&idp $=1254735573002$

INE. 2020. «Encuesta de Población Activa». Recuperado de https://www.ine.es/dyngs/INEbase/es/operacion.htm?c=Estadistica_C\&cid=1254736176918\&menu=ultiDatos\&idp=1254735976595
INE. 2021. «Estadística del padrón colectivo». Recuperado de https://Www.ine.es/dyngs/INEbase/es/operacion. htm? c=Estadistica_C\&cid=1254736177012\&menu=ultiDatos\&idp $=1254734710990$

Kennett, Chris. 2005. Sport, immigration and multiculturality: a conceptual análisis. Centre d'estudis Olimpics UAB, Barcelona.

Kennett, Chris. 2006. Deporte e inmigración en España: el papel del deporte en la integración de los ciudadanos. Barcelona: Centre d'Estudis Olímpics Universitat Autònoma de Barcelona (UAB)

Llopis Goig, Ramón. 2009. "Los inmigrantes y el deporte. Las prácticas deportivas de la población extranjera en el proceso de integración en la sociedad española". En Pautas de asentamiento de la población inmigrante: Implicaciones y retos socio-jurídicos, editado por C. Blanco y I. Barbero, 311-336. Madrid: Dykinson.

Llopis Goig, Ramón. 2010. "Inmigración y cultura deportiva. Una aproximación sociológica a las práctica y hábitos deportivos de la población extranjera residente en España". En Transitando por espacios comunes, editado por F. Checa, Á. Arjona y J. C. Checa, 231-258. Barcelona: Icaria

Mahía, Ramón. 2018. "Población extranjera residente en España. Evolución, características e integración económica". Anuario CIDOB de la Inmigración 2018: 80-113. DOI: doi.org/10.24241/AnuarioCIDOBInmi.2018.80

Mahía, Ramón. 2021. "Los efectos del COVID-19 sobre la inmigración en España: economía, trabajo y condiciones de vida" Anuario CIDOB de la Inmigración 2020: 68-81. DOI: doi.org/10.24241/AnuarioCIDOBInmi.2020.68

Maza, G. 2004. "Capital social del deporte". En Actividad física y deporte en sociedades multiculturales: ¿Integración o Segregación?, editado por T. Lleixà y S. Soler, 43-56. Barcelona: Horsori

Ministerio de Cultura y Deporte. 2015. "Encuesta de Hábitos Deportivos en España". Acceso 1 de mayo http://www.culturaydeporte.gob.es/servicios-al-ciudadano/estadisticas/cultura/mc/deportedata/habitos-deportivos/resultados-habitos-deportivos.html

Ministerio de Cultura y Deporte. 2020. "DEPORTEData". Acceso 1 de mayo. http://www.culturaydeporte.gob.es/servicios-al-ciudadano/estadisticas/cultu$\mathrm{ra} / \mathrm{mc} /$ deportedata/portada.html? $\mathrm{L}=0$

Ministerio de Educación y Formación Profesional. 2019. "Informe PISA 2018". Acceso 1 de mayo https:// www.observatoriodelainfancia.es/ficherosoia/documentos/5943_d_InformePISA2018-Espana1.pdf.

Molina, Fidel. 2010. "Deporte, interculturalidad y calidad de vida: nuevos modelos de integración social" Anduli № 9: 165-173. 
Morela, Eleftheria; Hatzigeorgiadis, Antonis; Sánchez, Xavier; Papaioannouet, Athanasios y Elbe, Anne-Marie. 2017. "Empowering youth sport and acculturation: Examining the hosts' perspective in Greek adolescents" Psycology of sport and exercise, vol. 30: 226-235.

Moscoso-Sánchez, David; De Léséleuc, Eric; Rodríguez-Morcillo, Luis; González- Fernández, Manuel; Pérez-Flores, Antonio y Muñoz-Sánchez, Víctor. 2017. “Expected outcomes of sport practice for inmates: A comparison of perceptions of inmates and staff" Journal of Sport Psychology, vol. 26, n. 1: 37-48.

Moscoso-Sánchez, David. 2020. "El Contexto Del Deporte En España Durante La Crisis Sanitaria De La COVID-19". Sociología Del Deporte 1 (1):15-19. https://doi.org/10.46661/socioldeporte.5000.

Olivé, Leon. 1999. "El Estado, la participación y el dialogo". En Multiculturalismo y Pluralismo, 217-234, editado por Leon Olivé. Barcelona: Paidos.

Pardo, Rodrigo, y García-Arjona, Noemí. 2011. “El Modelo de Responsabilidad: desarrollo de aspectos psicosociales en jóvenes socialmente desfavorecidos a través de la actividad física y el deporte". Revista de Psicología de la Educación, 6, 211-222

Pérez, Antonio Manuel y Muñoz, víctor Manuel. 2018. "Deporte, cultura y sociedad: un estado actual de la cuestión." Revista de humanidades, n. 34: 11-38

Pérez-Agote, Alfonso. 2016. "La religión como identidad colectiva: Ias relaciones sociológicas entre religión e identidad". Papeles del CEIC, vol. 2016/2, papel 155, CEIC (Centro de Estudios sobre la Identidad Colectiva), Universidad del País Vasco, http://dx. doi.org/10.1387/pceic.16178

Pfister, G. 2004. "Género y multiculturalidad: la apropiación del cuerpo y la práctica deportiva de las jóvenes inmigrantes". En Actividad física y deporte en sociedades multiculturales: Integración o segregación, editado por T. Lleixá y S. Soler, 57-80. Barcelona: Horsori.

Piedra de la Cuadra, Joaquín y Fernández-Gavira, Jesús. 2012. "Práctica Deportiva e Inclusión Social de las Mujeres Gitanas". Anduli: Revista Andaluza de Ciencias Sociales, n. 11: 117-131.

Putnam, Robert. 2007. E Pluribus Unum: Diversity and Community in the Twenty-first Century The 2006 Johan Skytte Prize Lecture. Scandinavian Political Studies, vol. 30 - No. 2

Ruiz, Luis; Rodríguez, Pedro; Martinek, Thomas; Schilling, Tammy; Durán, Luis y Jiménez, Pedro. 2006. “El Proyecto Esfuerzo: Un modelo para el desarrollo de la responsabilidad personal y social a través del deporte". Revista de Educación, 341, 933-958.
Sagarzazu, Itxasne. 2013. Integración social de colectivos inmigrantes a través del "campo deportivo" de Bourdieu. INGURUAK, 359-369.

Sánchez, Ricardo. 2010. "Políticas ciudadanas, inmigración y cultura: el caso del deporte en la ciudad de Barcelona". Revista de dialectología y tradiciones populares, 65(2): 337-358

Santos, Antonio y Balibrea, Kety. 2013. “El deporte y la integración social en imágenes: mujeres en forma contra la exclusión". Feminismo-s, 21, 139.

Santos, Antonio. 2019. "Activación e interiorización de valores empresariales a través del deporte: uso y abuso del deporte en la empresa y en la acción social". Revista Española de Sociología, 28 (3): 517-528. Doi: http://dx.doi.org/10.22325/fes/ res. 2019.15

Senneth, Richard. 2005. La corrosión del carácter: Las consecuencias personales del trabajo en el nuevo capitalismo. España: Anagrama.

Soler, Susanna., Ispizua, Marian., y Mendoza, Nuria. 2017. Integración social y deporte. En Sociología del deporte, coordinado por M. Garcia, N. Puig, F. Lagardera, R. Llopis y A. Vilanova, 145-167. Madrid: Alianza Editorial.

Standing, Guy. 2013. El precariado. Una nueva clase social. Barcelona: Pasado \& Presente

Tajfel, Henri. 1984. Grupos humanos y categorías sociales: estudios de psicología social. Herder: BarceIona.

Taylor, Charles. 1993 "El multiculturalismo y la política del reconocimiento". México: Fondo de cultura Económica.

Thuillier, Bastian, López, Víctor y Gallardo, Francisco. 2017a. "Inmigración, deporte y escuela. Revisión del estado de la cuestión". Retos: nuevas tendencias en educación física, deporte y recreación, (32): 19-24.

Thuillier, Bastian, López, Víctor y Gallardo, Francisco. 2017b. "La integración de los estudiantes inmigrantes en un programa de deporte escolar con fines de transformación social". Qualitative research in education, 6(1): 22-55.

Zinovyeva, Natalia; Felgueroso, Florentino y Vázquez Vega, Pablo. 2014. Inmigration and student achievement in Spain: Evidence from PISA. SERIES, 5 (1), p. 25-60.

Zubero, Imanol. 2006. "Las nuevas relaciones entre empleo e inclusión: flexibilización del trabajo y precarización vital". Documentación social, No 143: 11-30.

Zubero, Imanol. 2010. "Confianza ciudadana y capital social en sociedades multiculturales". Bilbao: Ikuspegi. 